\title{
Beyond the "STEM Pipeline": Expertise, Careers, and Lifelong Learning
}

\author{
John D. Skrentny ${ }^{1}$ (D) Kevin Lewis ${ }^{1}$
}

Accepted: 28 April 2021 / Published online: 15 June 2021

(C) The Author(s) 2021

\begin{abstract}
Studies of education and careers in science, technology, engineering, and math (STEM) commonly use a pipeline metaphor to conceptualize forward movement and persistence. However, the "STEM pipeline" carries implicit assumptions regarding length (i.e. that it "starts" and "stops" at specific stages in one's education or career), contents (i.e. that some occupational fields are "in" the pipeline while others are not), and perceived purpose (i.e. that "leakage," or leaving STEM, constitutes failure). Using the National Survey of College Graduates, we empirically measure each of these dimensions. First, we show that a majority of STEM workers report skills training throughout their careers, suggesting no clear demarcation between education and work. Second, we show that using on-the-job expertise requirements (rather than occupational titles) paints a very different portrait of the STEM workforce - and persistence in it (where substantial attrition remains evident, especially among women and African Americans). Third, we show that STEM-educated workers are well-prepared for but dissatisfied with non-STEM jobs, complicating our understanding of leaving. Collectively, these results recommend expanded conceptions of STEM education and careers and contribute to studies of science and engineering workforce transitions and diversity.
\end{abstract}

Keywords Education $\cdot$ Science $\cdot$ Engineering $\cdot$ STEM $\cdot$ Training $\cdot$ Work $\cdot$ Careers

John D. Skrentny

jskrentny@ucsd.edu

1 Department of Sociology, University of California-San Diego, 9500 Gilman Dr., La Jolla,

CA 92093-0533, USA 


\section{Introduction}

Social scientists have devoted considerable attention to understanding the "STEM pipeline" in the US, referring to education and work careers in science, technology, engineering, and math (STEM). The metaphor appears simple: People move through their education, which is akin to a singular pipe. As long as they major in STEM subjects, graduate, and work in STEM careers, they "persist" and the pipeline is considered successful. But if at some point they stop studying STEM subjects, choose a non-STEM major, or take a non-STEM job, they are said to have "leaked" (Cannady et al. 2014). Due to a national narrative that links the training of STEM workers to economic priorities (Mars et al. 2014), researchers and policymakers see leakage as a problem.

Others use a related metaphor, the "pathway," which encourages theorizing about multiple pathways, on ramps, and off ramps (Kannankutty 2007), but the pathway shares with the pipeline fundamental similarities, such as the ideas of forward movement as normative and leaving as a problem. Thus, when social scientists study why White and Asian males dominate the STEM workforce, they seek to uncover the discrimination and/or structural barriers that lead female, African American, and Latino students and workers to disproportionately leak from the pipeline (e.g., Cech et al. 2011; Rosser 2012; Glass et al. 2013).

The use of metaphor is common in the social sciences, and metaphors shape thinking about complex social phenomena (Brown 1976). However, metaphors can also mislead-particularly when their core assumptions are belied by the empirical reality they are meant to represent. Specifically, although the pipeline metaphor is often used to discuss and explain issues of preparation, persistence, and attrition in the STEM workforce, few studies have explored the meaning and scope conditions of these issues in practice.

We focus on producing a detailed, descriptive analysis of three fundamental dimensions of STEM training and employment. Each probes a basic assumption of the pipeline metaphor. The first assumption is pipeline length: Rather than assuming that the STEM pipeline "starts" and "stops" at certain stages in a person's career (typically ending with a degree), we empirically explore how long STEM-related learning actually lasts. The second assumption relates to pipeline contents: Rather than assuming that some fields are "in" the STEM pipeline and others are not, we explore whether different measures of STEM lead to different portraits of persistence. The third assumption is the pipeline's purpose: Rather than assuming that the goal of the STEM pipeline is retention (making "leakage" problematic), we explore what are the actual consequences of "leaving." We prefer this more neutral term (over the more pejorative "leaking") in recognition of the possible exercise of agency, which may be crucial in the narrower case of science research careers (Szelényi et al. 2016; Cañibano et al. 2019).

We do not claim that these are the only dimensions of STEM careers and training that can be fruitfully measured. We focus on these for three reasons. First, these dimensions relate to STEM graduates and their work lives-those who persisted through formal education and obtained a STEM degree-and who thus 
represent significant personal and institutional investment. Second, these dimensions can be clarified with data from the National Survey of College Graduates (NSCG), offering unique perspectives on movement through or out of the pipeline (see below). Third, each is fundamental to the ideas of persistence and leaving, and is key for theorizing how STEM education contributes to employment.

More specifically, if STEM skill development is common after college, then social scientists may fruitfully consider STEM learning as continuing into and possibly through careers, suggesting work is not a discrete stage from education. If STEM skills are utilized in fields of employment that are not typically considered STEM, then measures of persistence and leaving may need to be reassessed-with potentially important implications for the representation of women and people of color. Finally, if a STEM education confers benefits even to those who leave, then the meaning of leaving (or "leakage") — and the conclusion of pipeline "success" or "failure"-may be different than previously thought. STEM education may successfully prepare graduates for any career.

This analysis of leavers can contribute to a portrait of STEM persistence and also leaver outcomes. Leavers may easily adapt to jobs unrelated to their degrees, or face special challenges. If they show a range of positive outcomes, such as earning higher wages than non-STEM graduates in non-STEM jobs, it suggests new meanings of leaving STEM and the value and purpose of STEM education. Specifically, positive outcomes can mean leaving is a strategic exercise of agency, and STEM education is valuable for any career, whether in STEM or out. In that sense, leaving, while potentially problematic for contributing to job segregation, may not be a "failure" that needs to be fixed.

We first review literature regarding the continuation of STEM training, the measurement of persistence, and the actual consequences of leaving. We then use four waves of NSCG data to examine the characteristics of STEM careers. This survey is unique in offering multiple measures of the STEM workforce, including how (and for how long) one continues to acquire STEM skills and whether (and in what way) one actually employs these skills on the job.

We report three key findings. First, STEM workers commonly continue to learn STEM skills and knowledge nearly forty years after graduation, suggesting no clear demarcation between education/student and employment/worker stages of a STEM career. Second, many putatively non-STEM jobs actually require STEM expertise-and a revised view of STEM employment shows dramatically different portraits of leaving (though significant gaps remain for disadvantaged populations, especially women and African Americans). Third, STEM graduates employed in non-STEM jobs face mixed outcomes, appearing well-prepared but dissatisfied. Thus, the assumption that the purpose of a STEM education is only STEM worker production may not be warranted (since leavers appear wellprepared for non-STEM jobs) but their dissatisfaction raises concerns, and more research on the consequences of leaving would be fruitful. Collectively, these results recommend expanded conceptions of STEM education more generally (into lifelong learning for careers) and contribute to studies of science and engineering workforce transitions and diversity. 


\section{Three Dimensions of STEM Training and Careers}

\section{Pipeline Length: the Continuation of Training through STEM Careers}

Few studies have addressed the continuation of training into STEM careers. Some research posits that STEM training begins in the preschool years (e.g., Aldemir and Kermani 2017) and extends at least to mid-careers (e.g., Lowell et al. 2009). Work on academia specifically has identified different stages of science careers (Cañibano et al. 2019), noting how learning continues after the PhD but becomes more focused on building on prior research (Laudel and Gläser 2008: 397). The bulk of research, however, focuses on the STEM pipeline in K-12 and college education (see Xie et al. 2015). An assumption here is that graduation is a demarcation, where STEM graduates switch from learning skills to deploying skills. Treating education as a separate stage from work implies STEM graduates need no new learning to work in STEM jobs unless they decide to change careers.

Our interest is whether and how long learning might extend after graduation, or whether work is a discrete stage after education. STEM education may continue after a person accepts a STEM job if workers continue learning new skills or improving existing ones. Such learning is typically considered "training" rather than "schooling," takes different forms, and imparts more specific knowledge than formal schooling (Bills 2004; Bills and Hodson 2007). But this learning may be necessary to continue in a STEM career-and it might persist for decades, if not all the way up to retirement.

Social scientists have long identified a need for continual learning as a key feature of the postindustrial economy (Bills 2004). On-the-job learning can be necessary to keep up with changing job demands (Valdés and Barley 2016). Though jobs may require training for any number of reasons, STEM jobs are especially likely to require continual training to upgrade skills (Barley and Kunda 2004). The National Research Council reported that IT workers needed to spend 1.5-2 hours per day in some kind of training to maintain relevant skills (National Research Council 2001: p. 254). Technology-intensive jobs face such rapid skill obsolescence that "experienced STEM workers seeking employment in 2019 are often required to possess skills that were not required when they entered the labor market in 2007 or earlier" (Deming and Noray 2020: p. 1979).

If technological change is continually obsolescing skills, time since degree may be unrelated to the likelihood of skills-related learning. Research on this is mixed, however. One study in the Netherlands found that age (a proxy for time since degree) is negatively correlated with training among scientists and engineers (De Grip and Smits 2012). This suggests that either employers' willingness to provide training or workers' motivation to take it declines with age. Survey research on IT workers in the US, Canada, Australia, and England, however, has found that age is unrelated to work-related training (Charness and Fox 2010). Scant research has examined time elapsed since degree directly.

In sum, we know little about the continuation of STEM training through careers. If STEM workers continue to develop their skills and knowledge-especially if 
unrelated to time since degree - this would seem problematic for a metaphor that may conceptualize education and work as discrete stages. Lifelong learning may be essential for STEM persistence.

\section{Pipeline Contents: Measuring Persistence in STEM}

The pipeline metaphor entails another demarcation - in STEM or out—and implies that researchers have clear ideas about which degree fields and jobs are in. This assumption points to another dimension of STEM careers, which is the measure of persistence.

Defining STEM is not straightforward, whether we are talking about fields or jobs. The challenge may be especially acute for jobs, where the scientific, technical, or computing content of specific job titles may vary across time or employers. Although the National Research Council argued that "job content and performance are most important" for assessing pipeline persistence (1986:4), most research and government policies define STEM using degree fields and occupational titles. There is even inconsistency within the US government: The National Science Foundation (NSF) uses both "S\&E" (science and engineering) and "STEM," with varying fields and occupations in each, while the Department of Homeland Security's definition of STEM is different from both (National Science Board 2015; Department of Homeland Security 2016).

Social scientists' practices also vary, with little consensus or consistent rationales. "Math" is, by definition, part of STEM, but many researchers exclude social science, business, and education degrees and occupations, no matter how quantitative (e.g., Cech et al. 2011; Xie and Killewald 2012). Studies do not always explain categorization (e.g., Carnevale et al. 2011).

The lack of consensus may be due to inherent ambiguity in the STEM concept itself. One major example is health-oriented majors and occupations, where expertise includes life sciences. Morgan et al. (2013) categorize "doctoral-track medicine" as STEM, and Xie and Killewald's (2012) study of the "scientific pipeline" (they do not use the STEM acronym) excludes medical doctors.

Moreover, the scientific and technological components of fields and jobs change over time. Though evidence may be weak for an overall shift in technical skills demands (Handel 2016), researchers have long identified changes in skill requirements in some jobs, especially those requiring a college degree. This literature points to more jobs utilizing STEM skills in recent decades—what we might call a limited "STEMification" in the nation's job markets. ${ }^{1}$ The most prominent example may be finance "quants" (Patterson 2011); indeed, DHS now classifies quantitative finance and economics as STEM fields (Redden 2018). Similar are people with degrees in mathematical sciences who work for companies like Facebook and use technology to enhance advertising (Vance 2011).

\footnotetext{
${ }^{1}$ For example, the theory of "skill-biased technological change" asserts that technology changes have increased skill requirements over time but education has not kept up, leading to increasing premiums for the college-educated and increasing inequality in society (Goldin and Katz 2008; see also Hout 2012).
} 
Two other aspects of STEMification are important. First is the creation of new jobs in the innovation sector that require STEM skills. For instance, the fastest growing and highest paying job for entry level workers in 2019, "data scientist," is still so new it lacks a category in Department of Labor and National Science Foundation statistics (Hagan 2019); it is therefore unclear if it is counted in occupational definitions of STEM. Second is the growth in sheer numbers of tech jobs. Between the early 2000s and 2012, jobs in the internet sector increased by $634 \%$. Other STEM areas that saw explosive growth were jobs in pharmaceuticals/life sciences, software, and R\&D (Moretti 2012). New tech workers require managers to oversee them, project managers to oversee the development of new products, and sales representatives to market these products (National Science Board 2015). All of these jobs may utilize or require advanced technological (STEM) skills.

The literature thus shows no consensus on which fields and jobs constitute STEM, and thus on the meaning of persistence in a STEM career. It also shows growing STEM components of existing jobs; new jobs (like data scientist) that would seem to be STEM; and growing numbers of STEM jobs, requiring new STEM managers and salespeople. Importantly, this calls into question literature on women and minorities because accurately measuring persistence and leaving from the pipeline requires clearly specifying what it means to be in or out. Defining STEM persistence to include jobs that require college-level STEM skills-rather than relying on old occupational categories that predate the rise of the internet-may shed new light on this issue and could reveal more persistence than previously suspected.

\section{Pipeline Purpose: Understanding the Consequences of Leaving}

A final important dimension of STEM training and careers that the pipeline metaphor obscures is the perceived purpose of a STEM education. This is crucial to interpret the meaning of leaving. Is STEM education only a process for producing STEM workers? Should leaving be considered a problem for researchers to study and policymakers to mitigate?

Research reveals little discussion of these basic questions. A place to start are the differing rationales for studying the STEM pipeline: concerns about having enough STEM workers to meet demand (Rosser 2012; Xie and Killewald 2012: 9); having enough STEM workers to drive economic growth (Carnevale et al. 2011; Rosser 2012; Xie, Fang, and Shauman 2015); and equalizing access to STEM jobs (e.g., Cech et al. 2011; Rosser 2012; Morgan et al. 2013; Wynn and Correll 2018). However, these rationales are not without problems. First, research indicates shortages occur in only a few STEM fields (e.g., software development; Xue and Larson 2015; Teitelbaum 2014). Second, what exactly constitutes innovation-driven growth, and which workers are crucial for producing it, are unknown (Kuehn and Salzman 2018). Third, regarding equal outcomes, very few studies systematically examine what happens to workers who leave STEM. If leaving somehow benefits the leavers-beyond the generic effect of a college degree (Hout 2012) — then leaving may not be failure or even a problem (though equalizing access and improving diversity in STEM may 
be social goods in their own right). Assessing outcomes, negative or positive, can thus inform perceptions of the purpose of STEM education.

One area to search for possible STEM education effects on leavers is wages. Few studies have explored whether STEM graduates in non-STEM jobs make more, the same, or less than non-STEM graduates in similar jobs. ${ }^{2}$ It may be that the STEMification processes turning more jobs into STEM jobs also add technical components to non-STEM jobs-components that do not require college-level STEM skills but for which a STEM degree nevertheless provides superior preparation. Alternately, a STEM education may convey significant but more latent benefits (such as ways of thinking, collaborating, or problem-solving) that provide generalizable advantages in the workplace, leading to higher wages for STEM graduates across all sectors.

A second area where we may find effects of STEM education for leavers is happiness or satisfaction at work. Research on STEM education and later job satisfaction is very limited. One study found that STEM majors tend to be satisfied with their jobs, a result driven by earnings (Wolniak and Pascarella 2005). More generally, job satisfaction tends to be lower when workers perceive a mismatch between their education and their job, regardless of education level, job attributes, and worker characteristics (Lee and Sabharwal 2016). If STEM pipeline leavers are unhappy due to mismatch, leaving may imply failure.

A final way we might assess the success or failure of STEM education is in alternative evidence that STEM education benefits STEM graduates who work in nonSTEM jobs. Wage is one indirect measure, but superior career preparation may not be recognized with higher wages. Another approach would be to examine likelihoods of taking skills-related training. We understand that training to improve jobrelated skills and knowledge may be a noisy (and inverse) measure of preparation for work. Training can indicate a skills deficit that is being ameliorated or employers' belief that workers are worthy of investment (Bills 2004; Waddoups 2016); similarly, the absence of training may indicate either that there is no skills deficit or that a deficit exists but is not being ameliorated for some reason, such as lack of opportunities or motivation.

Still, an analysis of training can contribute to a portrait of the preparation and "success" of STEM leavers, who may struggle to adapt to jobs unrelated to their degrees-or they may find their STEM degrees prepare them well. Specifically, a combination of lower likelihood of training, higher wages, and higher job satisfaction could indicate that leavers (compared to non-STEM graduates in non-STEM jobs) benefit from their STEM education; that STEM education prepares individuals for jobs in and outside of STEM; and that leaving, while still potentially problematic for contributing to occupational segregation, is not "failure" in the sense of negative outcomes for workers.

\footnotetext{
${ }^{2}$ Addressing a different but related question, Carnevale et al. (2011) found that many STEM graduates voluntarily leak or "divert" to non-STEM jobs-especially managerial, professional, and healthcare professional jobs-for higher earnings. However, this study's definition of STEM might be too narrow (and thus its definition of leakage too broad) insofar as it focused on occupational titles rather than actual utilization of STEM skills.
} 


\section{Data}

To empirically address the above questions, we utilized the National Survey of College Graduates (NSCG). The NSCG is a biennial, nationally-representative survey conducted by the NSF and designed to provide data on American college graduates. A variety of scholars have utilized it, including sociologists (e.g., Morgan 2000) and economists (e.g., Hunt 2016).

For the present study, the NSCG has several advantages. To our knowledge, it is the only dataset that contains information on the educational and occupational histories of respondents; information on skills-related training after graduation; and a unique approach to defining STEM, commensurate with our empirical interests. Specifically, the survey follows the NSF definitions of S\&E (comparable to STEM), S\&E-related (explained below), and non-S\&E (non-STEM) fields and jobs. But it also contains a question about respondents' use of STEM expertise at their jobs. The inclusion of questions about training and this alternative measure of STEM employment allow for rich explorations of multiple dimensions of the STEM workforce.

In most cycles, the NSCG focused only on STEM workers. However, in 1993, 2003, 2010, 2013, and 2015, it provided representative coverage of the nation's college-educated population. Specifically, the target population consisted of all individuals who (1) lived in the US during the survey reference week, (2) had at least a bachelor's degree, and (3) were under the age of 76. We omit the 1993 NSCG, because it did not contain the question identifying STEM expertise usage on the job. Employing the remaining four waves of data allows us to discern whether our results are robust over time and also to comment tentatively on trends.

In all analyses that follow, we focus on a subset of available data defined by two criteria. First, we omitted respondents who were unemployed during the reference week (and so for whom questions regarding current occupation were inapplicable). Second, we omitted respondents whose first bachelor's degree was in an "S\&Erelated field" - a mixed category consisting predominantly of "Health" fields (e.g., nursing, physical therapy, audiology) but also "Science and mathematics teacher education," "Technology and technical fields," and "Other S\&E-related fields" (actuarial science and architecture/environmental design). This group included fewer than $10 \%$ of employed respondents in all four years, and it is unclear where they should fit in the primary STEM/non-STEM distinction with which this paper is concerned. In the subsections that follow, we provide additional detail on the central variables in our analyses. Additional, subsidiary variables (namely, those used as control variables or for a single analysis) are described as they are introduced.

\section{STEM/Non-STEM Education}

To distinguish between STEM and non-STEM educational specializations, we use the major of each respondent's bachelor's degree (or first bachelor's, if applicable). The NSF classifies majors into seven categories: (1) computer and mathematical sciences; (2) biological, agricultural and environmental life sciences; (3) physical 
and related sciences; (4) engineering; (5) social and related sciences; (6) non-S\&E fields; and (7) S\&E-related fields. As noted above, we omitted respondents in category (7) from all analyses. We considered categories (1) through (4) to represent "STEM" educational backgrounds and (5) and (6) to represent "non-STEM" backgrounds (see Xie and Killewald 2012 for a similar exclusion of social scientists from the definition of "STEM").

\section{STEM/Non-STEM Occupation}

Classifying occupations as STEM or non-STEM is also central to the aims of this study. To explore the meaning of STEM persistence, we use and compare two different measures of the STEM workforce. First, the NSF applies the same sevencategory classification to categorize the occupation of employed respondents. We consider the same four groups as constituting STEM occupations and the remaining groups as non-STEM. ${ }^{3}$ Second, to explore the possibility that many jobs not normally considered STEM now require STEM skills-as well as the possibility that many putative STEM workers' job activities do not include strictly technical tasks (National Science Board 2015)—we include a measure based on respondents' selfreported usage of college-level STEM skills on the job. Specifically, respondents indicate whether their job duties "require the technical expertise of a bachelor's degree or higher in engineering, computer science, math, or the natural sciences." We considered respondents who said "yes" to be STEM and "no" to be nonSTEM workers. We use this latter measure in our analyses of the duration of training and the consequences of leaving, and both measures in our analysis of STEM persistence.

\section{Worker Training}

Our focus on training continuation and consequences of leaving both relate to the use of training to improve skills. Social scientists have long used worker surveys to study participation in training (e.g., Knoke and Ishio 1998). We measure training using a binary variable derived from the following question: "During the past 12 months, did you take any work-related training, such as workshops or seminars?" Respondents were instructed to include conferences or professional meetings only if they attended a training session and to omit college coursework for which they were enrolled in a degree program. Those who said "yes" were also prompted to answer a series of follow-up inquiries regarding the reasons for their training. In the analyses

\footnotetext{
${ }^{3}$ In order to provide a more comprehensive analysis-and recognizing that workers in virtually any occupation may or may not say their job requires STEM expertise-we do not exclude "S\&E-related" occupational fields the same way we exclude "S\&E-related" educational fields (and, for the second section of results, we consider these fields as "non-STEM"). However, as a reviewer helpfully pointed out, the health professions in particular may warrant special attention-especially insofar as continuing education ("training") is required for licensing in many health professions. Consequently, except in Table 2 (where healthcare workers are explicitly identified), we replicated all other analyses in this paper after excluding "health-related occupations" and report whether or how results varied in footnotes.
} 
that follow, "skills-related training" refers to all respondents who indicated that they took training "to improve skills or knowledge in your current occupational field" (regardless of whether or what other options were selected). The full list of available options is reproduced in the "Appendix". 4

These questions provide a rare opportunity to examine the prevalence (and correlates) of skills-related training in the US. Nonetheless, their limitations are important to acknowledge. First, the questions do not differentiate between distinct instances of training, each potentially motivated by different reasons. Second, the questions focus on formal settings such as workshops or seminars. As such, they exclude informal, potentially independent self-training practices that employees might pursue (see, e.g., Bills and Hodson 2007) — and if anything, should therefore provide a conservative estimate of continued education in the STEM workforce. Third, we do not know if the question focusing on improving "skills or knowledge in your current occupational field" relates to STEM skills specifically. STEM workers may take training in their current occupational field that improves their skills or knowledge related to project management, teamwork, or leadership. However, given the research, some of which is cited above, on rapidly changing technology and rapidly obsolescing skills, there is strong reason to believe that much of this training is related to STEM skills specifically.

\section{Results}

\section{Continuation of Training into STEM Careers}

To assess the continuation of and demarcations in STEM education into the careers of STEM workers, we first look at the prevalence of training among incumbent STEM workers (whom we define as those using college-level STEM expertise on the job). Though different from formal schooling for a degree, skills-related training can be considered an extension of STEM education because it similarly entails preparation for work.

Figure 1 shows the prevalence of skills-related training among STEM workers across all four survey years. Although there is a slight downward trend over timefrom $59.3 \%$ of workers in 2003 to $57.2 \%$ of workers in 2015 - in all four years, over half of all STEM workers report taking skills-related training in the last year. ${ }^{5}$ It is clear that learning for work is very common for STEM workers and graduating with a degree does not typically end STEM education. ${ }^{6}$

\footnotetext{
4 Some options were available in certain survey years but not others and the wording of commensurable options varied slightly between 2003 and later surveys. Across all survey years, however, skills development was by far the most common reason respondents cited for training, accounting for 93-94\% of all respondents who trained.

5 If we omit workers in health-related occupations, the prevalence of training decreases very slightly (by $.8 \%$ in $2003,1.3 \%$ in $2010,1.4 \%$ in 2013 , and $1.7 \%$ in 2010 ) but the overall pattern is similar.

${ }^{6}$ In addition to asking respondents the reasons they took training, the NSCG asks which among these reasons was most important. If we instead count only those respondents who said skills improvement was the most important reason for their training, the prevalence of skills-related training is predictably lower: $38.1 \%$ in $2003,37.4 \%$ in $2010,35.3 \%$ in 2013 , and $34.7 \%$ in 2015 .
} 
$65 \%$

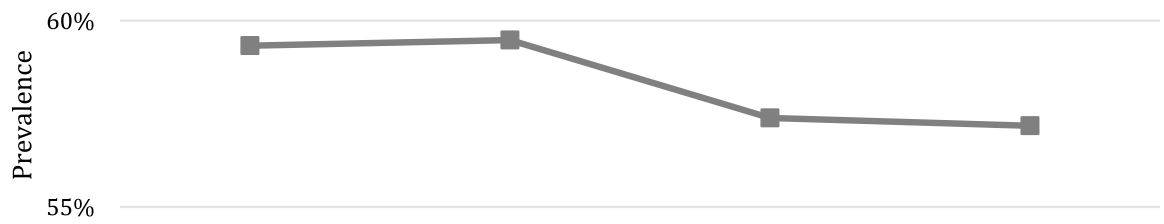

$50 \%$

2003

2010

2013

2015

NSCG year

Fig. 1 Proportion of STEM workers who reported taking skills-related training in the past 12 months, by NSCG survey year

Although the majority of STEM workers in each survey year can thus still be considered to be both learners and workers, these results could instead be interpreted differently if we argue that over $40 \%$ of STEM workers do not seem to be learning new skills. We would caution against this interpretation, however. First, the data for each year only document training in the preceding twelve months, so workers who do not train in a given year may still train later. Second, as noted above, the NSCG prompts respondents to think of training only in terms of "workshops or seminars" and other formal settings. For both of these reasons, these results likely understate the amount of (formal and informal) learning occurring throughout STEM workers' careers.

Next, we look at the prevalence of skills-related training depending on the number of years since respondents received their most recent degree. This distribution is presented in Fig. 2. Across all four survey years-and up to thirty years after obtaining their most recent degree- it is still the case that over half of STEM workers have taken formal training sometime in the last year to improve skills or knowledge. ${ }^{7}$ After this, the prevalence of training begins to decline, although consistently over $40 \%$ of STEM workers continue to train until 40 years after their most recent degree and consistently over $30 \%$ of STEM workers continue to train until 45 years after their most recent degree (sample sizes at this point are considerably smaller, reducing precision). ${ }^{8}$

\footnotetext{
7 This finding holds even when workers in health-related occupations are excluded.

${ }^{8}$ To formalize this analysis, we ran a simple logistic regression predicting the likelihood of skills-related training based on time elapsed since most recent degree. Both linear and quadratic terms were statistically significant at $p<.05$ for three of four survey years-suggesting the likelihood of training reaches a maximum at 11.7 years after graduation in 2003 and 2010 and 17 years after graduation in 2015. The
} 


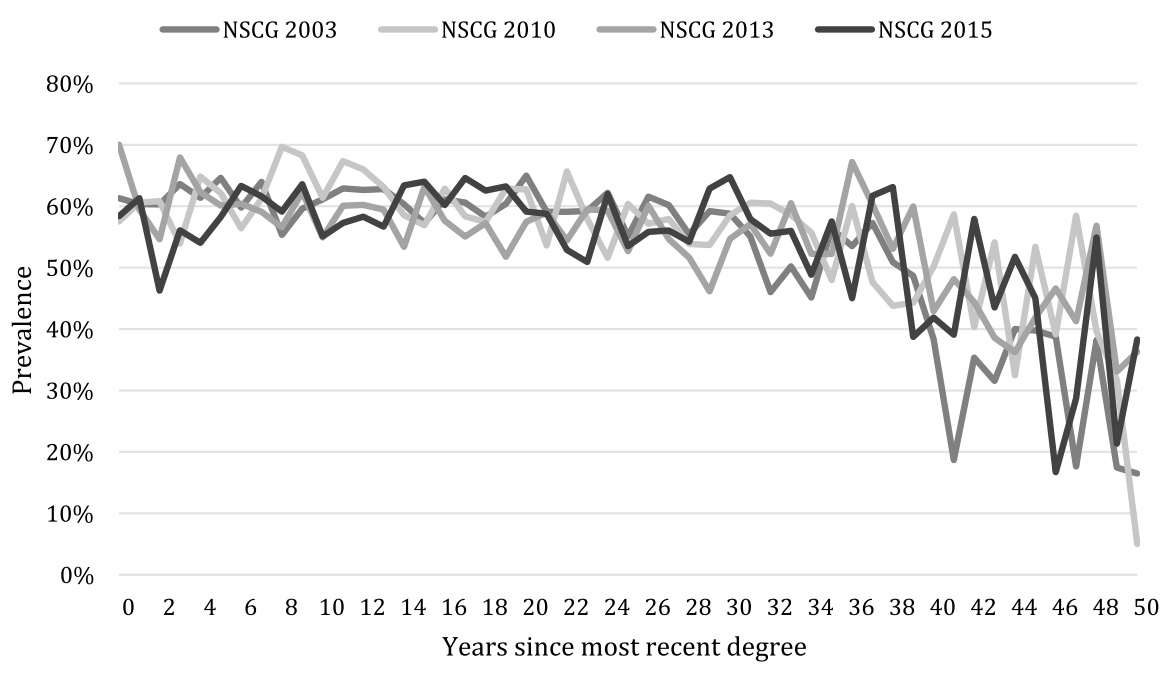

Fig. 2 Proportion of STEM workers who reported taking skills-related training in the past 12 months, by years since most recent degree and NSCG survey year

In summary, using a very conservative measure of training, we find that more than half of workers who use college-level STEM skills on the job indicate they are still learning after receiving their last degree. Moreover, this learning continues at nearly consistent frequencies across survey years and does not show attenuation until decades after the degree was obtained. Indeed, great percentages of STEM workers continue to learn job-related skills and knowledge well into the advanced stages of their careers-perhaps even until retirement.

\section{Measuring STEM Persistence}

The NSCG contains multiple modes of measuring whether respondents work in STEM jobs: one based on traditional NSF classifications derived simply from occupational field and one based on respondents' individualized self-reports of whether their job requires "the technical expertise of a bachelor's degree or higher in engineering, computer science, math, or the natural sciences." These two measures provide divergent impressions of the extent and composition of STEM persistence and leaving and alternate means of measuring STEMification.

First, in Table 1, we note the overall percentage of STEM graduates who currently work in STEM jobs (as described earlier, we consider a "STEM graduate" anyone who earned their first bachelor's degree in one of four "STEM" fields). Interestingly, according to both measures, the proportion of STEM graduates who work in STEM has not changed much between 2003 and 2015: It decreases by about $1.5 \%$

Footnote 8 (continued)

quadratic term was not significant in 2013 but the linear term (significant at $p<.001$ ) indicated that the log-odds of training decrease by .01 with each successive year. 
Table 1 Percentage of STEM graduates who work in STEM, by two definitions of STEM
Occupation definition (\%) Expertise

definition

(\%)

\begin{tabular}{lll}
\hline NSCG year & & \\
2003 & 41.96 & 70.54 \\
2010 & 39.63 & 72.45 \\
2013 & 39.58 & 72.04 \\
2015 & 40.48 & 72.68 \\
\hline
\end{tabular}

using the occupational definition and increases by about $2 \%$ using the expertise definition. However, the magnitude of persistence is markedly different: If we use the occupational definition of STEM, about $40 \%$ of STEM graduates have persisted in each survey year; if we use the expertise definition, this proportion rises considerably (to over 70\%). In other words, even though only $40 \%$ of STEM graduates go on to work in "STEM occupations," $70 \%$ of STEM graduates claim to utilize STEM skills on the job.

What accounts for this discrepancy? In Table 2, we examine career choices of STEM graduates more closely. Specifically, we report the top ten jobs in each of the four permutations of whether a job (1) is classified as a STEM occupation and (2) requires STEM expertise. The smallest category of workers-containing, on average, $2.2 \%$ of STEM graduates across survey years - are those who work in "STEM occupations" but say their job does not require STEM skills. Eight of the top ten jobs are considered "computer and information scientists" by the NSF. The largest category of workers-consisting of almost $40 \%$ of STEM graduates-are those who work in STEM occupations and say their job requires STEM skills. The top ten jobs include a broad mix of computer and information scientists but also engineers, chemists, and biological scientists.

Across survey years, about a quarter of STEM graduates leave according to both definitions of the STEM workforce: employees who neither work in STEM jobs nor report using STEM skills. About half of these workers are in the top ten jobs listed, largely health- and management-related occupations as well as sales and marketing occupations. Finally - and most provocatively for our understanding of STEMification and leaving - about a third of STEM graduates report working in non-STEM occupations but nevertheless utilizing STEM skills. About $61 \%$ of these workers are

\footnotetext{
${ }^{9}$ Predictably, this story changes slightly once we omit workers in health-related occupations-who by definition do not work in STEM according to their occupation (so the denominator decreases but the numerator stays the same). Excluding these respondents, according to the occupation definition, the percentages of STEM graduates who persist in STEM increases by about 5 or 6 percentage points each year and according to the expertise definition, the percentages of STEM graduates who persist in STEM increase by about 2 or 3 percentage points each year. Results from replications by field of degree, gender, and ethnicity (as shown in Tables 3 and 4) are available by request.
} 
Table 2 Top 10 occupations for STEM graduates who leave/stay in STEM, by two definitions of STEM

\begin{tabular}{|c|c|c|c|c|}
\hline $\begin{array}{l}\text { Occupation } \\
\text { definition }\end{array}$ & STEM & STEM & Non-STEM & Non-STEM \\
\hline $\begin{array}{l}\text { Expertise } \\
\text { definition }\end{array}$ & STEM & Non-STEM & STEM & Non-STEM \\
\hline $\begin{array}{l}\% \text { STEM } \\
\text { graduates }\end{array}$ & $38.24 \%$ & $2.17 \%$ & $33.69 \%$ & $25.90 \%$ \\
\hline 1. & $\begin{array}{l}\text { Computer engi- } \\
\text { neers- software }\end{array}$ & $\begin{array}{l}\text { Computer support } \\
\text { specialists }\end{array}$ & $\begin{array}{l}\text { Diagnosing/treating } \\
\text { practitioners }\end{array}$ & $\begin{array}{l}\text { Diagnosing/treating } \\
\text { practitioners }\end{array}$ \\
\hline 2. & $\begin{array}{l}\text { Software develop- } \\
\text { ers- applications } \\
\text { and systems } \\
\text { software }\end{array}$ & $\begin{array}{l}\text { Other computer } \\
\text { information sci- } \\
\text { ence occupations }\end{array}$ & $\begin{array}{l}\text { Top-level managers, } \\
\text { execs, admins }\end{array}$ & $\begin{array}{l}\text { RNs, pharmacists, } \\
\text { dieticians, thera- } \\
\text { pists, physician asst, } \\
\text { nurse practitioners }\end{array}$ \\
\hline 3. & $\begin{array}{l}\text { Electrical and elec- } \\
\text { tronics engineers }\end{array}$ & $\begin{array}{l}\text { Computer system } \\
\text { analysts }\end{array}$ & $\begin{array}{l}\text { Other management } \\
\text { related occupa- } \\
\text { tions }\end{array}$ & $\begin{array}{l}\text { Other management } \\
\text { related occupations }\end{array}$ \\
\hline 4. & $\begin{array}{l}\text { Mechanical engi- } \\
\text { neers }\end{array}$ & $\begin{array}{l}\text { Network and } \\
\text { computer systems } \\
\text { administrators }\end{array}$ & $\begin{array}{l}\text { Teachers: Second- } \\
\text { ary- computer, } \\
\text { math or sciences }\end{array}$ & $\begin{array}{l}\text { Top-level managers, } \\
\text { execs, admins }\end{array}$ \\
\hline 5. & $\begin{array}{l}\text { Civil, including } \\
\text { architectural/sani- } \\
\text { tary engineers }\end{array}$ & $\begin{array}{l}\text { Software develop- } \\
\text { ers- applications } \\
\text { and systems } \\
\text { software }\end{array}$ & $\begin{array}{l}\text { Engineering manag- } \\
\text { ers }\end{array}$ & $\begin{array}{l}\text { Accountants, auditors, } \\
\text { and other financial } \\
\text { specialists }\end{array}$ \\
\hline 6. & $\begin{array}{l}\text { Computer system } \\
\text { analysts }\end{array}$ & Medical scientists & $\begin{array}{l}\text { Other mid-level } \\
\text { managers }\end{array}$ & Other administrative \\
\hline 7. & $\begin{array}{l}\text { Computer support } \\
\text { specialists }\end{array}$ & Web developers & $\begin{array}{l}\text { Computer program- } \\
\text { mers }\end{array}$ & $\begin{array}{l}\text { Other marketing and } \\
\text { sales occupations }\end{array}$ \\
\hline 8. & $\begin{array}{l}\text { Chemists, except } \\
\text { biochemists }\end{array}$ & $\begin{array}{l}\text { Database adminis- } \\
\text { trators }\end{array}$ & $\begin{array}{l}\text { Accountants, audi- } \\
\text { tors, and other } \\
\text { financial special- } \\
\text { ists }\end{array}$ & Sales- retail \\
\hline 9. & $\begin{array}{l}\text { Other computer } \\
\text { information sci- } \\
\text { ence occupations }\end{array}$ & $\begin{array}{l}\text { Computer engi- } \\
\text { neers- software }\end{array}$ & $\begin{array}{l}\text { Computer and infor- } \\
\text { mation systems } \\
\text { managers }\end{array}$ & $\begin{array}{l}\text { Insurance, securities, } \\
\text { real estate and busi- } \\
\text { ness services }\end{array}$ \\
\hline 10. & Biological scientists & Biological scientists & $\begin{array}{l}\text { RNs, pharmacists, } \\
\text { dieticians, thera- } \\
\text { pists, physician } \\
\text { asst, nurse practi- } \\
\text { tioners }\end{array}$ & $\begin{array}{l}\text { Health technologists } \\
\text { and technicians }\end{array}$ \\
\hline
\end{tabular}

Note: This table was generated using average statistics across all four survey years (2003, 2010, 2013, 2015). The classification scheme changed slightly after 2003; categories only present in 2003 are omitted

in the jobs listed. The most common is "diagnosing/treating practitioners," including dentists, psychiatrists, physicians, and veterinarians. Multiple categories include various kinds of managers. The list also includes secondary teachers (in "computer, math or sciences"); computer programmers; financial specialists; and other healthrelated occupations, such as nurses and physician assistants. The finding that health occupations appear in both STEM expertise and non-STEM expertise categories was not anticipated; we return to this issue in the conclusion. 
Table 3 Percentage of STEM graduates who work in STEM, by field of degree and two definitions of STEM

\begin{tabular}{lll}
\hline & $\begin{array}{l}\text { Occupation } \\
\text { definition }\end{array}$ & $\begin{array}{l}\text { Expertise } \\
\text { definition }\end{array}$ \\
\hline Computer and mathematical sciences & & \\
NSCG 2003 & $49.34 \%$ & $74.94 \%$ \\
NSCG 2010 & $48.35 \%$ & $73.94 \%$ \\
NSCG 2013 & $47.80 \%$ & $73.35 \%$ \\
NSCG 2015 & $50.29 \%$ & $74.66 \%$ \\
Biological, agricultural and environmental life sciences & & \\
NSCG 2003 & $19.34 \%$ & $53.01 \%$ \\
NSCG 2010 & $19.60 \%$ & $58.63 \%$ \\
NSCG 2013 & $19.91 \%$ & $56.78 \%$ \\
NSCG 2015 & $18.84 \%$ & $55.72 \%$ \\
Physical and related sciences & & \\
NSCG 2003 & $42.47 \%$ & $69.92 \%$ \\
NSCG 2010 & $40.67 \%$ & $73.30 \%$ \\
NSCG 2013 & $39.57 \%$ & $72.01 \%$ \\
NSCG 2015 & $41.89 \%$ & $74.86 \%$ \\
Engineering & & \\
NSCG 2003 & $56.47 \%$ & $82.81 \%$ \\
NSCG 2010 & $51.52 \%$ & $83.43 \%$ \\
NSCG 2013 & $51.42 \%$ & $84.60 \%$ \\
NSCG 2015 & $52.52 \%$ & $85.55 \%$ \\
\hline
\end{tabular}

Now that we know where leavers go, Table 3 shows where they began. In other words, it provides persistence details by comparing our two measures of STEM employment for specific STEM degree fields. Both measures agree that the greatest persistence occurs among bachelor's degrees in engineering: Across all survey years, over half of such graduates go on to work in STEM occupations and over $80 \%$ report that their job requires STEM expertise.

Meanwhile, leaving is most common among degrees in the biological, agricultural and environmental life sciences-where fewer than $20 \%$ go on to work in STEM fields and fewer than $60 \%$ report that their job requires STEM expertise. ${ }^{10}$ Interestingly, while the occupation definition consistently suggests leaving is far more widespread than the expertise definition, the magnitude of this difference varies by degree field. For instance, in 2015, twice as many graduates with a computer/

\footnotetext{
${ }^{10}$ One concern is this finding is an artifact of the wording of the expertise measure, where respondents with a degree in the life sciences may not realize that a question about expertise in "the natural sciences" refers to them. Although we return to this issue in the conclusion, we are less concerned here because the relatively high degree of leaving among life science graduates is also documented using the occupationbased measure of STEM — which presumably does not suffer from this limitation.
} 
Table 4 Percentage of STEM graduates who work in STEM, by gender, ethnicity, and two definitions of STEM
Occupation

definition

Expertise definition

\begin{tabular}{|c|c|c|}
\hline \multicolumn{3}{|l|}{ Gender } \\
\hline \multicolumn{3}{|l|}{ Male } \\
\hline NSCG 2003 & $45.69 \%$ & $73.65 \%$ \\
\hline NSCG 2010 & $43.76 \%$ & $76.14 \%$ \\
\hline NSCG 2013 & $44.14 \%$ & $76.77 \%$ \\
\hline NSCG 2015 & $46.21 \%$ & $77.93 \%$ \\
\hline \multicolumn{3}{|l|}{ Female } \\
\hline NSCG 2003 & $31.32 \%$ & $61.65 \%$ \\
\hline NSCG 2010 & $29.41 \%$ & $63.30 \%$ \\
\hline NSCG 2013 & $29.21 \%$ & $61.26 \%$ \\
\hline NSCG 2015 & $28.16 \%$ & $61.37 \%$ \\
\hline \multicolumn{3}{|l|}{ Ethnicity } \\
\hline \multicolumn{3}{|l|}{ White } \\
\hline NSCG 2003 & $40.63 \%$ & $70.32 \%$ \\
\hline NSCG 2010 & $37.69 \%$ & $71.71 \%$ \\
\hline NSCG 2013 & $38.41 \%$ & $71.52 \%$ \\
\hline NSCG 2015 & $38.61 \%$ & $71.42 \%$ \\
\hline \multicolumn{3}{|l|}{ Asian } \\
\hline NSCG 2003 & $52.66 \%$ & $74.74 \%$ \\
\hline NSCG 2010 & $50.61 \%$ & $77.83 \%$ \\
\hline NSCG 2013 & $49.00 \%$ & $77.77 \%$ \\
\hline NSCG 2015 & $53.66 \%$ & $80.78 \%$ \\
\hline \multicolumn{3}{|l|}{ Black } \\
\hline NSCG 2003 & $36.41 \%$ & $63.51 \%$ \\
\hline NSCG 2010 & $35.70 \%$ & $65.08 \%$ \\
\hline NSCG 2013 & $33.95 \%$ & $64.43 \%$ \\
\hline NSCG 2015 & $31.59 \%$ & $62.99 \%$ \\
\hline \multicolumn{3}{|l|}{ Latino } \\
\hline NSCG 2003 & $37.80 \%$ & $68.34 \%$ \\
\hline NSCG 2010 & $35.69 \%$ & $72.90 \%$ \\
\hline NSCG 2013 & $35.07 \%$ & $70.70 \%$ \\
\hline NSCG 2015 & $33.08 \%$ & $71.19 \%$ \\
\hline
\end{tabular}

mathematical sciences degree leave under the occupation definition (50\%) compared to the expertise definition (25\%), whereas leaving among engineering majors is over three times as common under the occupation definition (47\%) compared to the expertise definition (14\%).

Our two measures of STEM work also present contrasting trends over time. According to the occupation definition, the proportion of STEM graduates who enter STEM jobs remains fairly constant between 2003 and 2015-except among engineering majors, where there is a slight decrease. According to the expertise definition, however, computer/mathematical science majors are the only graduates who 
were as likely to use STEM skills on the job in 2015 as in 2003-all other STEM graduates were more likely to use STEM skills in the 2010s than in 2003. This difference might be explained by the increased use of software (STEMification).

Finally, Table 4 shows how contrasting measures of persistence impact our measurement of gender and ethnic inequalities in STEM. The occupation definition of STEM again underestimates the scale of persistence vis-à-vis the expertise definition. Both definitions show a familiar portrait of inequality: Women are less likely to persist in STEM than men and Blacks and Latinos are less likely to persist in STEM than Whites. However, the specific contours of these differences, and trends over time, vary. For instance, the occupation definition suggests male persistence in STEM has remained fairly constant while female persistence increased slightly, whereas the expertise definition suggests female persistence has remained fairly constant whereas male STEM graduates have been increasingly likely to use STEM expertise on the job since 2003. The expertise definition shows different trends with respect to ethnicity as well: While all ethnic groups except Asians are less likely to work in STEM occupations in 2015 compared to 2003, all ethnic groups except Blacks are more likely to use STEM skills in 2015 compared to 2003. In fact, by 2015, about $71 \%$ of White and Latino STEM graduates and $81 \%$ of Asian graduates use STEM skills on the job, while Black STEM graduates continue to exhibit the least persistence, at only $63 \%$.

If STEM education is meant to prepare people for STEM jobs, then accurately identifying STEM jobs is an essential first step to assess the success of school-towork transitions. The fact that large percentages of STEM graduates report using college-level STEM skills in a wide variety of jobs suggests persistence in STEMand a STEM workforce that extends into a variety of different fields, including management and health.

\section{Consequences of Leaving STEM}

In this section, we look at STEM graduates who have left STEM beyond simply identifying where they work. Specifically, we assess whether a college-level STEM education is valuable even if workers do not believe they are using college-level STEM expertise, and whether leaving should thus be considered a failure of STEM education. Could a STEM education prepare people to work even outside of STEM? Might leaving - taking STEM education to non-STEM jobs-even represent a kind of success?

Here we look again at the data on training. We focus in Table 5 on workers who say their job does not require the expertise of a bachelor's degree in STEM and assess the impact of having one. Specifically, we run four logistic regression models-one for each survey year-where the response variable is whether the respondent took skills-related training in the past year. To isolate as much as possible the 
Table 5 Predictors of attending skills-related training for jobs not requiring STEM expertise

\begin{tabular}{|c|c|c|c|c|c|c|c|c|}
\hline & \multicolumn{2}{|l|}{2003} & \multicolumn{2}{|l|}{2010} & \multicolumn{2}{|l|}{2013} & \multicolumn{2}{|l|}{2015} \\
\hline & Coef & SE & Coef & SE & Coef & SE & Coef & SE \\
\hline \multicolumn{9}{|l|}{ Demographic characteristics } \\
\hline Age & -.002 & .002 & .001 & .005 & .005 & .004 & .004 & .004 \\
\hline \multicolumn{8}{|l|}{ (Male) } & \\
\hline Female & $.299 * * *$ & .038 & .042 & .076 & $.196 * * *$ & .056 & .109 & .070 \\
\hline \multicolumn{9}{|l|}{ Ethnicity } \\
\hline Asian & $-.177 * *$ & .061 & -.061 & .133 & $-.238^{*}$ & .098 & $-.391 * * *$ & .112 \\
\hline Black & -.096 & .051 & .137 & .111 & -.019 & .093 & -.101 & .097 \\
\hline Latino & $-.118^{*}$ & .049 & .086 & .140 & $.230 * *$ & .088 & .056 & .092 \\
\hline Other & .026 & .096 & .094 & .219 & .248 & .148 & -.117 & .172 \\
\hline \multicolumn{9}{|l|}{$\begin{array}{l}\text { Citizenship/visa status } \\
\text { (Native citizen) }\end{array}$} \\
\hline $\begin{array}{l}\text { Naturalized citizen/ } \\
\text { permanent resident }\end{array}$ & $-.356^{* * *}$ & .044 & $-.360 * * *$ & .097 & $-.371 * * *$ & .086 & -.010 & .090 \\
\hline Temporary resident & $-.688 * * *$ & .153 & $-1.036 * * *$ & .283 & $-.638 * * *$ & .192 & -.218 & .439 \\
\hline \multicolumn{9}{|l|}{$\begin{array}{l}\text { (No children in house- } \\
\text { hold) }\end{array}$} \\
\hline Children in household & $.241 * * *$ & .041 & $.330 * * *$ & .083 & $.204 * * *$ & .057 & -.001 & .070 \\
\hline $\begin{array}{l}\text { Female*children in } \\
\text { household }\end{array}$ & $-.112^{*}$ & .053 & -.009 & .114 & -.046 & .084 & .188 & .097 \\
\hline \multicolumn{9}{|l|}{ Educational characteristics } \\
\hline \multicolumn{9}{|l|}{$\begin{array}{l}\text { Field of first bachelor's } \\
\text { degree }\end{array}$} \\
\hline STEM & $-.171 * * *$ & .042 & $-.142 *$ & .061 & $-.196 * * *$ & .050 & $-.246 * * *$ & .064 \\
\hline \multicolumn{8}{|l|}{ Highest degree type } & \\
\hline Master's & $.297 * * *$ & .032 & $.515^{* * * *}$ & .084 & $.356^{* * * *}$ & .052 & $.402 * * *$ & .059 \\
\hline Doctorate & $-.267 * * *$ & .069 & -.011 & .146 & -.170 & .100 & $-.308 * *$ & .107 \\
\hline Professional & $1.040 * * *$ & .054 & $1.233 * * *$ & .118 & $1.137 * * *$ & .086 & $1.267 * * *$ & .100 \\
\hline $\begin{array}{l}\text { Years since most recent } \\
\text { degree }\end{array}$ & $-.009 * * *$ & .002 & -.007 & .005 & $-.013 * * *$ & .004 & -.007 & .004 \\
\hline \multicolumn{9}{|l|}{ Occupational characteristics } \\
\hline \multicolumn{9}{|l|}{$\begin{array}{l}\text { Employer sector } \\
\text { (For-profit) }\end{array}$} \\
\hline Education & $.931 * * *$ & .040 & $1.191^{* * *}$ & .087 & $1.035^{* * *}$ & .059 & $1.214^{* * *}$ & .069 \\
\hline Self-employed & $.178 * *$ & .056 & .205 & .143 & .151 & .088 & .165 & .110 \\
\hline Non-profit & $.741 * * *$ & .054 & $.749^{* * *}$ & .099 & $.673^{* * *}$ & .073 & $.706^{* * *}$ & .080 \\
\hline Government & $.640 * * *$ & .041 & $.695 * * *$ & .128 & $.588 * * *$ & .077 & $.848 * * *$ & .085 \\
\hline
\end{tabular}


Table 5 (continued)

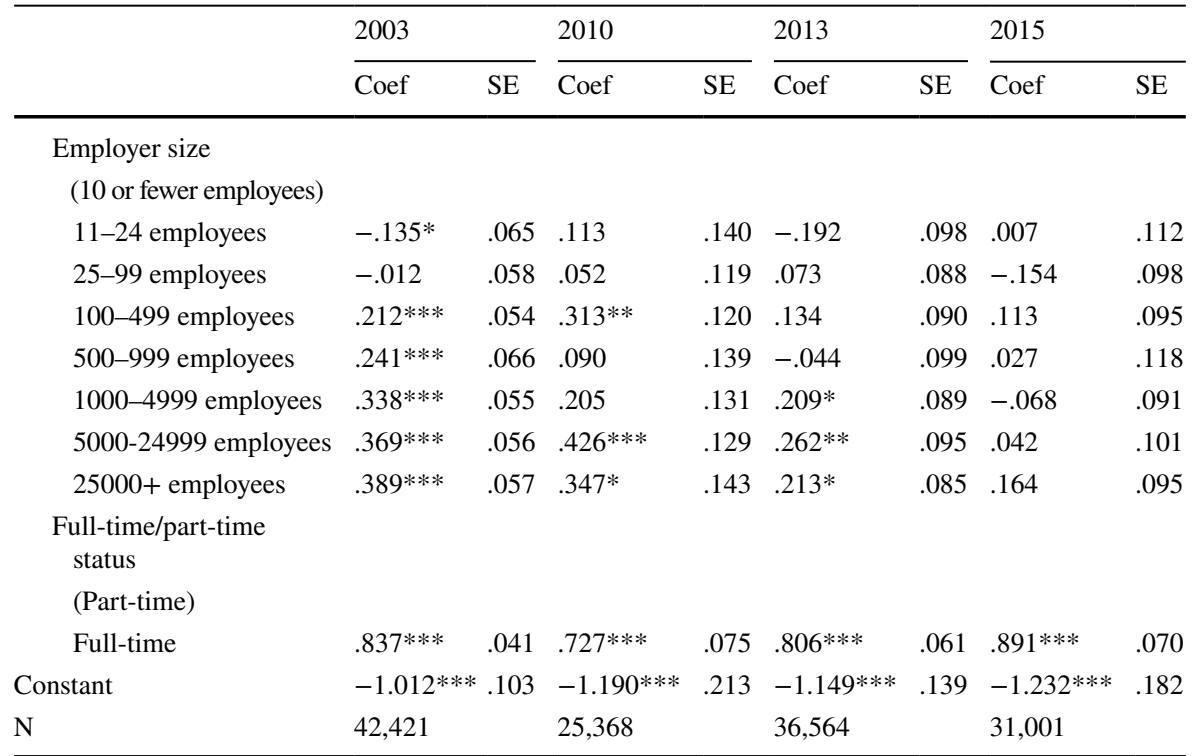

Note: Logistic regression coefficients. For categorical variables, reference category is in parentheses ${ }^{*} p<.05 ; * * p<.01 ; * * * p<.001$

effect of a STEM education, explanatory variables include a wide array of demographic, educational, and occupational factors that could potentially affect the likelihood of training (e.g., Knoke and Ishio 1998). ${ }^{11}$

Several trends are noteworthy. The likelihood of skills training is greater for those with a master's degree and (especially) a professional degree in all four years and those who work in for-profit jobs are consistently least likely to train (compared to working in government, education, or non-profits). A variety of other terms show inconsistent effects over time (for instance, having children in the household is associated with an increased likelihood of training in all years except 2015, and women are more likely than men to train in 2003 and 2013). Of primary interest to us, however, is that having a bachelor's degree in STEM (compared to non-STEM) is associated with a significantly lower likelihood of training to improve skills in all four survey years.

Though the negative effect of a STEM degree is robust controlling for a variety of factors that might affect training, it is possible that STEM degree holders in non-STEM jobs work in different non-STEM jobs-jobs where learnable skills or knowledge are less likely to be required. To test this possibility, we replicated

\footnotetext{
${ }^{11}$ Here and in most subsequent analyses—as well as in significance tests reported earlier—standard errors are calculated using replicate weight files provided by the NSF. Due to small sample sizes, replicate weights could not be employed for our robustness check controlling for occupation and so traditional standard errors are used.
} 
all four models including fixed effects for the occupation of each respondent (using the level of precision reflected in Table 2)-ensuring we are comparing the likelihood of training by those with and without STEM degrees in identical jobs (as precisely as the NSCG can measure them). The results show that in all years except 2010 (where the sample size is smallest), the effect continues to be negative and significant: Even at the same (non-STEM) jobs, individuals with STEM degrees are less likely to train than those with non-STEM degrees.

To assess whether STEM and non-STEM graduates working in non-STEM jobs differ with respect to other outcomes, we precisely replicated the four models in Table 5, but using eleven alternative response variables (and standard linear regression, rather than logistic regression, as appropriate): one measuring respondents' (annualized) salary; one measuring respondents' overall job satisfaction (assessed on a four-point scale where 4 = "very satisfied," $3=$ "somewhat satisfied," 2 = "somewhat dissatisfied," and 1 = "very dissatisfied"); and nine measuring respondents' job satisfaction (assessed identically) regarding specific dimensions of their job.

Results are summarized in Table 6. To emphasize trends, we do not report control variables or the values of coefficients (available from the corresponding author by request) and instead focus on whether the effect of having a STEM bachelor's degree (compared to a non-STEM bachelor's degree) is statistically significant, and in what direction (positive or negative).

First, we find there is little indication of a salary advantage: In three of the four years, the salaries of STEM and non-STEM graduates are statistically indistinguishable (STEM graduates make significantly more in 2003 only). Second, in all four years, STEM graduates are less satisfied than non-STEM graduates with their non-STEM jobs. Third, regarding the source of their job dissatisfaction, the NSCG provides many

Table 6 How STEM graduates compare with non-STEM graduates in jobs that do not require STEM expertise

\begin{tabular}{|c|c|c|c|c|}
\hline & 2003 & 2010 & 2013 & 2015 \\
\hline Salary & higher* & & & \\
\hline Job satisfaction (overall) & lower* & lower* & lower* & lower** \\
\hline \multicolumn{5}{|l|}{ Job satisfaction (specific items) } \\
\hline Salary & & & & lower* \\
\hline \multicolumn{5}{|l|}{ Benefits } \\
\hline \multicolumn{5}{|l|}{ Job security } \\
\hline Job location & & & lower* & lower* \\
\hline Opportunities for advancement & lower* & & & lower* \\
\hline Intellectual challenge & lower*** & lower** & lower*** & lower*** \\
\hline Level of responsibility & lower* & & & lower** \\
\hline Degree of independence & & & lower*** & lower** \\
\hline Contribution to society & higher** & & & \\
\hline
\end{tabular}

Note: Cell values reflect the sign (positive/negative) and significance level of the "STEM" (field of first bachelor's degree) effect in OLS regressions with the response variables listed above. Control variables are suppressed (and include all other effects in Table 6). Empty cells reflect non-significant effects

$* p<.05 ; * * p<.01 ; * * * p<.001$ 
reasons for respondents to choose, but only one reason is statistically significant in all four years: Compared to non-STEM graduates, STEM graduates in non-STEM jobs are consistently less satisfied with the intellectual challenge of their jobs. ${ }^{12}$

Taken together, these results suggest mixed, though mostly negative, conclusions regarding the preparation that STEM degrees provide for jobs that do not require college-level STEM skills. The lack of a discernible salary boost suggests no special advantage from a STEM degree. Meanwhile, the consistent comparative dissatisfaction of STEM graduates in non-STEM jobs, particularly regarding their intellectual challenge, suggests that a STEM education might actually over-prepare employees for non-STEM work-leading them to be bored.

It is more challenging to interpret the finding of less training for skills and knowledge by STEM graduates in non-STEM jobs. This pattern could mean they have no skills deficit, or their deficit is not being addressed, or something else. It is difficult to imagine that STEM graduates face discrimination that excludes them from training. The large array of control variables_-including gender, ethnic background, and the presence of children in the household-also means our findings are unlikely to be an artifact of other differences between STEM and non-STEM graduates. Unfortunately, other possible explanations, such as differing ambitions or ability levels of STEM and non-STEM graduates, are impossible to assess here. ${ }^{13}$

The explanation we suggest is linked to the overall portrait of outcomes, and specifically to the finding of STEM graduates' intellectual dissatisfaction in non-STEM jobs. Though these jobs do not require college-level STEM expertise per se, they may still have technical, scientific, or mathematical components that give STEMeducated workers a comparative advantage_enough that they need not train, but not enough for consistent wage rewards. Put another way, non-STEM graduates may be entering non-STEM jobs with a skills deficit-and STEM graduates with a skills surplus - which is also why they do not find these jobs to be "intellectually challenging." This interpretation coincides with other evidence. For example, a survey of recruiters for Fortune 1000 companies found that $60 \%$ saw workers with STEM degrees as "more in demand" than those without and that "STEM skills are in demand by employers for jobs that are traditionally considered non-STEM"

\footnotetext{
12 This pattern holds even controlling for occupation. All major trends discussed in this section of results (related to differences between STEM and non-STEM graduates in terms of training, overall job satisfaction, and satisfaction with intellectual challenge) also persist (and increase in magnitude) when healthrelated occupations are excluded. Other noteworthy findings in Table 6 that might fruitfully be explored elsewhere are that in 2003 (and only in 2003) STEM graduates expressed that they were more satisfied than non-STEM graduates with their (non-STEM) job's contribution to society; and in 2015, STEM graduates were less satisfied than non-STEM graduates with more aspects of their work than in any other year-six of nine dimensions.

13 One is that these workers, who may have chosen to not use their STEM education in their careers, are also choosing not to improve their skills or knowledge - they have, in a sense, given up career ambition. If this was the case, however, we might expect them to have lower salaries than non-STEM graduates; they do not. Another possibility is that STEM graduates are faster learners than non-STEM graduatesso fast that they are less likely to need formal training. This is certainly possible; some research shows STEM majors have higher scores on the SAT, GRE, and other standardized tests (Wai et al. 2009; Wai 2015). The premise of STEM education efforts in schools and in policies, however, is that anyone can perform STEM work if properly trained.
} 
(Bayer Corporation 2014: 620). Still, the finding of lower satisfaction casts doubt on the notion that STEM education serves the joint purpose of supplying workers for STEM and non-STEM jobs-a conclusion we return to below.

\section{Discussion and Conclusion}

We have understood the STEM pipeline metaphor as a way to think about education and career processes, but also as containing assumptions about how STEM training and career processes can and should work. In contrast, we have sought to empirically describe important dimensions of the STEM workforce, demonstrating and transcending the limits of this metaphor as a frame for education, training, and career research.

We have argued that understanding STEM education and career processes can be improved in three ways: understanding (1) the duration and continuation of STEM training into STEM careers (or the "length" of the pipeline and whether it has critical demarcations); (2) the measurement of persistence in STEM (or the "contents" of the pipeline, and which jobs should be considered "in" or "out"); and (3) the consequences of leaving (or the "purpose" of the pipeline and whether "leakage" is a problem or denotes failure). The payoff is a more nuanced and empirically accurate picture of workforce development in this important area.

What does this picture look like? Regarding the continuation of training, we found that more than half of STEM graduates who have moved into STEM work continue skills-related training. Moreover, this learning continues with no discernible decline even 30 years after degree attainment (after 40 years, over $40 \%$ are still training). Though entering the world of work means getting paid for the deployment of skills and knowledge, learning does not stop at any clearly demarcated point (or pipeline "end")—-belying the notion of a clear separation between education and work or between student and worker.

Survey limitations do not allow a more in-depth exploration of this learning, but a major takeaway is for scholars and policymakers to consider STEM education as a lifelong phenomenon and not only a matter of formal, degree-oriented education. Preschool, K-12, college, and graduate school experiences are certainly important and crucial parts of STEM training. But only studying these stages of learning implies that career preparation ends at graduation and that obstacles and barriers that occur after the end of degree-focused learning are not significant. If that message is imparted to learners, it could be a recipe for disillusionment. For scholars and policymakers concerned about representation of women and ethnic minorities in STEM, it is essential to follow the entire educational journey of these individuals for as long as it lasts. Put simply, work is commonly another stage of learning-one that STEM workers commonly take on for life (see Bills 2004 for a similar argument regarding a broader range of careers).

Regarding the measurement of STEM persistence, we found that defining STEM jobs in terms of whether bachelors-level STEM expertise is required (based on the subjective reports of workers themselves) significantly affects the amount of persistence and leaving. Namely, there are far more jobs that require high-level STEM 
skills and knowledge than the definition of STEM based on occupational titles implies, suggesting a large number of jobs are indeed STEMified.

If we consider these STEM-expertise jobs to be part of the STEM workforceentailing at once a more flexible and precise measurement of pipeline "contents" that does not simply define entire categories of employees as "in" our "out," regardless of their actual job experiences-our overall estimates of persistence and leaving change radically. Leaving plummets from $60 \%$ to $30 \%$. Put another way, while only $40 \%$ of STEM graduates work in traditional STEM occupations, $70 \%$ continue to use STEM skills on the job. This gap is explained especially by moves to managerial and health occupations, though the range of jobs requiring STEM expertise is very wide. We also found that although the STEM pipeline is usually discussed as a monolithic aggregate, persistence varies greatly by field of degree, as over $80 \%$ of engineering majors use STEM skills in their work compared to less than $60 \%$ of biology/life sciences majors.

This understanding of persistence also provides a very different picture of STEM diversity. Specifically, we see that at the stage of full-time employment, persistence is a bigger problem for women than for racial and ethnic minorities. By 2015, women's persistence doubles when we define STEM work in terms of expertise, and it reduces somewhat the gap with men. However, women's persistence remains significantly lower-a difference of more than $16 \%$. A key takeaway here is that factors related to leaving STEM at the stage of work are not limited to traditional STEM occupations.

The race/ethnicity story during full-time employment shows different patterns. First, except for the White deficit relative to Asians in traditional STEM occupations, none of the leaving differences reach double digits. Second, whereas the African American persistence deficit increases slightly when we use the expertise definition of STEM work, for Latinos, the persistence deficit vis-à-vis Whites shrinks from a few percentage points to nearly zero. Meanwhile, the White deficit compared to Asians is almost cut in half, down to less than $10 \%$.

Employment persistence problems thus affect different workers differently. Women face significant pushes or pulls out of STEM at high rates with either definition of STEM work. Since STEM expertise jobs are often managerial, African Americans and Asian Americans may face obstacles moving to the managerial track (on discrimination against Asians in management; see Varma 2002). When we consider all STEM expertise jobs collectively, the reduction of Latino leaving is a surprising finding that warrants further study.

The large impact that the STEM-expertise definition has on measurements of persistence should give researchers pause regarding conclusions that rely on occupational definitions only. There is little reason to think that occupational labels created several decades ago capture what workers do today. Like the "hybrid research careers" in the study of science research (Cañibano et al. 2019), STEM careers throughout the economy are undergoing change as old, non-STEM jobs like "animator" are replaced with new STEM jobs like "image-mastering engineering" (Moretti 2012: 45). In research science, there are jobs where STEM skills are likely necessary: research foundation program officers, science journal editors, and research lab 
managers. Any of these positions may require at least college-level STEM expertise, and be considered part of the STEM workforce.

Finally, regarding the consequences of leaving STEM and the purpose of a STEM degree, our results are more complex. We found that STEM graduates in non-STEM jobs made similar incomes to non-STEM graduates in non-STEM jobs, but were less likely to report skills-related training and were less satisfied with their jobs, specifically the lack of intellectual challenge. We cautiously interpret these results to suggest that even non-STEM jobs may be undergoing (a lighter version of) STEMification. In these cases, skills learned by STEM majors are useful, but only such that they are less likely to need training - and rather than exceling at their jobs, STEM graduates are bored by them. This dissatisfaction indicates that while STEM education provides excellent preparation for a broad range of jobs, it is indeed a problem, if not necessarily a "failure," when STEM graduates leave to take non-STEM jobs. Coupled with the lack of income advantage that such workers experience, this may be especially problematic to policymakers hoping to frame STEM degrees as a means of social mobility.

Our work is limited in a number of ways. One is that our focus on STEM education does not take into account people who start with non-STEM degrees and move into STEM jobs. The pipeline metaphor posits a singular pipeline with leaks and does not easily accommodate this population, which may include $15 \%$ of STEM workers (Kannankutty 2007). Although it is possible to reconceptualize the pipeline as two flows (STEM and non-STEM graduates) heading to one destination (jobs requiring STEM expertise), we do not explore this issue here.

We also acknowledge weaknesses in our measures, although we believe they are the most faithful to our empirical interests that are currently available. Earlier, we noted that the NSCG questions on training - which do not record intensity or frequency and prompt respondents to think of training narrowly and formally-likely understate our key results. Another concern is that the STEM expertise question prompts respondents to think about a degree in math, computer science, or engineering, while using the vaguer term "natural sciences" as a catch-all for life sciences, chemistry, physics, and others. Respondents who use skills and knowledge based in these latter fields may not see the expertise question as directed at them and thus be counted out of our measure of STEM workers (see note 10). 
This is especially relevant to the medical workers who show up in both STEM expertise and non-STEM expertise categories and yet are considered only "S\&Erelated" according to the NSF's occupation definition of STEM. Although results from our replications with health-related occupations omitted were highly consistent with those reported in the main text, the categorization of medical occupations is a longstanding ambiguity in STEM research and policymaking. Some medical workers may not affirmatively respond to the appropriate survey question despite their use of college-level life sciences, and so they appear to leave even with the expertise definition of STEM. This would understate the level of pipeline persistence, such that STEM persistence is even more common than we report. Future research could explore the potentially unique issues of STEM learning, persistence, and measurement within specialized occupational fields such as medicine and academia.

Future research could also fruitfully explore other dimensions of STEM training and career processes. For example, we know little about how much STEM education is necessary to maintain forward movement in STEM-expertise jobs. Is it necessary to major in STEM subjects, or to minor in them, is taking certain college-level classes sufficient, and how does this vary by field? At the career stage, how much training is necessary for career maintenance and advancement, what forms can this learning take, how does this vary by field, and how does it vary by employment sector (industry, academia, government R\&D)? Here, research may fruitfully take into account the rise of non-degree credentials, such as certificates, that have been prominent in IT fields, especially for those who already have a postsecondary degree (Ewert and Kominski 2014). Future research might also examine STEM graduates who do not use their STEM expertise on their jobs. Who are these workers; why did they leave STEM; and if they are dissatisfied with the intellectual challenges of their jobs, could their skills be better utilized by their employers?

We encourage researchers to approach STEM education and employment as a complex social infrastructure linking educational institutions to workplaces, careers, and lifelong learning. For anyone interested in STEM jobs and spurring innovation with equal opportunity, the findings reported here suggest attention would be fruitfully given to the full range of STEM learning and occupational experiences.

Acknowledgments The authors thank Mary Blair-Loy, Erin Cech, John Finamore, Daniel Goroff, Michael Handel, Nirmala Kannankutty, Natalie Novick, Brian Powell, Hal Salzman, Karina Shklyan, Mitchell Stevens, April Sutton, and the reviewers and editor of this journal for helpful comments.

Funding Support for this research was provided by Alfred P. Sloan Foundation Award B2012-51 and NSF National Center for Science and Engineering Statistics Award 1322945. 


\section{Appendix}

Table A1 Wording of "reasons for training" questions on the NSCG

Available options in the 2003 NSCG

"To gain further skills or knowledge in your occupational field"

"To increase opportunities for promotion, advancement, or higher salary"

"To facilitate a change in your occupational field"

"Required or expected by employer"

"For licensure or certification"

"To learn skills or knowledge needed for a recently acquired position"

"Other-Specify"

Available options in the 2010, 2013, and 2015 NSCG

"To improve skills or knowledge in your current occupational field"

"To increase opportunities for promotion or advancement in your current occupational field"

"To facilitate a change to a different occupational field"

"Required or expected by employer"

"For licensure or certification in your current occupational field"

"For leisure or personal interest"

"Other-Specify"

Note: Bolded options are considered "skills-related training" in the main text

Open Access This article is licensed under a Creative Commons Attribution 4.0 International License, which permits use, sharing, adaptation, distribution and reproduction in any medium or format, as long as you give appropriate credit to the original author(s) and the source, provide a link to the Creative Commons licence, and indicate if changes were made. The images or other third party material in this article are included in the article's Creative Commons licence, unless indicated otherwise in a credit line to the material. If material is not included in the article's Creative Commons licence and your intended use is not permitted by statutory regulation or exceeds the permitted use, you will need to obtain permission directly from the copyright holder. To view a copy of this licence, visit http://creativecommons.org/licen ses/by/4.0/.

\section{References}

Aldemir, Jale, and Hengameht Kermani. 2017. Integrated STEM Curriculum: Improving Educational Outcomes for Head Start Children. Early Child Development and Care 187: 1694-1706.

Barley, Stephen A., and Gideon Kunda. 2004. Gurus, Hired Guns, and Warm Bodies: Itinerant Experts in a Knowledge Economy. Princeton, NJ: Princeton University Press.

Bayer Corporation. 2014. The Bayer Facts of Science Education XVI: US STEM Workforce ShortageMyth or Reality? Fortune 1000 Talent Recruiters on the Debate. Journal of Science Education and Technology 23: 617-623.

Bills, David B. 2004. The Sociology of Education and Work. Malden, MA: Blackwell.

Bills, David B., and Randy Hodson. 2007. Worker Training: A Review, Critique, and Extension. Research in Social Stratification and Mobility 25: 258-272.

Brown, Richard H. 1976. Social Theory as Metaphor: On the Logic of Discovery for the Sciences of Conduct. Theory and Society 3: 169-197.

Cañibano, Carolina, Richard Wooley, Eric J. Iversen, Sybille Hinze, Stefan Hornbostel, and Jakob Tesch. 2019. A Conceptual Framework for Studying Science Research Careers. Journal of Technology Transfer 44: 1964-1992. 
Cannady, Matthew A., Eric Greenwald, and Kimberly N. Harris. 2014. Problematizing the STEM Pipeline Metaphor: Is the STEM Pipeline Metaphor Serving Our Students and the STEM Workforce? Science Education 98: 443-460.

Carnevale, Anthony P., Nicole Smith, and Michelle Melton. 2011. STEM: Science, Technology, Engineering, Mathematics. Washington, DC: Georgetown University Center on Education and the Workforce.

Cech, Erin, Brian Rubineau, Susan Silbey, and Carroll Seron. 2011. Professional Role Confidence and Gendered Persistence in Engineering. American Sociological Review 76: 641-666.

Charness, Neil, and Mark C. Fox. 2011. Formal Training, Older Workers, and the IT Industry. In Aging and Working in the New Economy: Changing Career Structures in Small IT Firms, eds. Julie Ann McMullin and Victor W. Marshall, 143-162. Northampton, MA: Edward Elgar.

Deming, David J., and Kadeem Noray. 2020. Earnings Dynamics, Changing Job Skills, and STEM Careers. The Quarterly Journal of Economics 135: 1965-2005.

Department of Homeland Security. 2016. STEM Designated Degree Program List, Effective May 10, 2016. Available at https://www.ice.gov/sites/default/files/documents/Document/2016/stem-list.pdf

Ewert, Stephanie, and Robert Kominiski. 2014. Measuring Alternative Educational Credentials: 2012. Washington, DC: US Census Bureau.

Glass, Jennifer, Sharon Sassler, Yael Levitte, and Katherine M. Michelmore. 2013. What's So Special about STEM? A Comparison of Women's Retention in STEM and Professional Occupations. Social Forces 92(2): 723-756.

Grip, Andries, and Wendy Smits. 2012. What Affects Lifelong Learning of Scientists and Engineers? International Journal of Manpower 33: 583-597.

Goldin, Claudia, and Lawrence F. Katz. 2008. The Race between Education and Technology. Cambridge, Mass.: Harvard University Press.

Hagan, Shelly. 2019. These Are the Highest Paying Jobs for the Class of 2019. Bloomberg May 15. Available at https://www.bloomberg.com/news/articles/2019-05-15/big-data-skills-earn-high-pay-for-todays-college-graduates

Handel, Michael J. 2016. What Do People Do at Work? A Profile of U.S. Jobs from the Survey of Workplace Skills, Technology, and Management Practices (STAMP). Journal for Labour Market Research 49: $177-197$.

Hout, Michael. 2012. Social and Economic Returns to College Education in the United States. Annual Review of Sociology 38: 379-400.

Hunt, Jennifer. 2016. Why Do Women Leave Science and Engineering? ILR Review 69: 199-226.

Kannankutty, Nirmala. 2007. Multiple Pathways to Science and Engineering Employment: Characteristics of the U.S. S\&E Workforce. 2007 Atlanta Conference on Science, Technology and Innovation Policy. [No city] IEEE, pp. 177-184.

Knoke, David, and Yoshito Ishio. 1998. The Gender Gap in Company Job Training. Work and Occupations 25(2): 141-167.

Kuehn, Daniel, and Hal Salzman. 2018. The Engineering Labor Market: An Overview of Recent Trends. In U.S. Engineering in a Global Economy, eds. Richard B. Freeman and Hal Salzman, 11-46. Chicago: University of Chicago Press.

Laudel, Grit, and Jochen Gläser. 2008. From Apprentice to Colleague: The Metamorphosis of Early Career Researchers. Higher Education 55: 387-406.

Lee, Young-joo, and Meghna Sabharwal. 2016. Education-Job Match, Salary, and Job Satisfaction Across the Public, Non-Profit, and For-Profit Sectors: Survey of Recent College Graduates. Public Management Review 18(1): 40-64.

Lowell, B. Lindsay, Harold Salzman, Hamutal Bernstein, and Everett Henderson. 2009. Steady as She Goes? Three Generations of Students Through the Science and Engineering Pipeline. Paper presented at the Annual Meetings of the Association for Public Policy Analysis and Management, Washington, D.C.

Mars, Matthew M., Kate Bresonis, and Katalin Szelényi. 2014. Science and Engineering Doctoral Student Socialization, Logics, and the National Economic Agenda: Alignment or Disconnect? Minerva 52(3): 351-379.

Moretti, Enrico. 2012. The New Geography of Jobs. Boston: Houghton Mifflin Harcourt.

Morgan, Laurie A. 2000. Is Engineering Hostile to Women? An Analysis of Data from the 1993 National Survey of College Graduates. American Sociological Review 65(2): 316-321.

Morgan, Stephen L., Daphna Gelbgiser, and Kim A. Weeden. 2013. Feeding the Pipeline: Gender, Occupational Plans, and College Major Selection. Social Science Research 42: 989-1005.

National Research Council. 1986. Engineering Infrastructure Diagramming and Modeling. Washington, DC: National Academy Press. 
National Research Council. 2001. Building a Workforce for the Information Economy. Washington, DC: The National Academies Press.

National Science Board. 2015. Revisiting the STEM Workforce: A Companion to Science and Engineering Indicators 2014. Arlington, VA: National Science Foundation.

Patterson, Scott. 2011. The Quants: How a Small Band of Maths Wizards Took Over Wall Street and Nearly Destroyed It. New York: Random House Business Books.

Redden, Elizabeth. 2018. Is Econ STEM? Inside Higher Ed, February 19, available at https://www.insid ehighered.com/admissions/article/2018/02/19/economics-departments-reclassify-their-programs-stemattract-and-help

Rosser, Sue V. 2012. Breaking into the Lab: Engineering Progress for Women in Science. New York: NYU Press.

Szelényi, Katalin, Kate Bresonis, and Matthew M. Mars. 2016. Who Am I versus Who Can I Become?: Exploring Women's Science Identities in STEM Ph.D. Programs. The Review of Higher Education 40(1): 1-31.

Teitelbaum, Michael. 2014. Falling Behind? Boom, Bust and the Global Race for Scientific Talent. Princeton: Princeton University Press.

Valdés, Gonzalo, and Stephen R. Barley. 2016. Be Careful What You Wish For: The Learning Imperative in Postindustrial Work. Work and Occupations 43: 466-501.

Vance, Ashlee. 2011. This Tech Bubble Is Different. Bloomberg Businessweek. April 14. Available at https:// www.bloomberg.com/news/articles/2011-04-14/this-tech-bubble-is-different.

Varma, Roli. 2002. High-Tech Coolies: Asian Immigrants in the US Science and Engineering Workforce. Science as Culture 11: 337-361.

Waddoups, C. Jeffrey. 2016. Did Employers in the United States Back Away from Skills Training During the Early 2000s? ILR Review 69(2): 405-434.

Wai, Jonathan. 2015. Your College Major Is a Pretty Good Indication of How Smart You Are. Quartz February 3. Available at https://qz.com/334926/your-college-major-is-a-pretty-good-indic ation-of-how-smart-you-are/

Wai, Jonathan, David Lubinski, and Camilla P. Benbow. 2009. Spatial Ability for STEM Domains: Aligning Over 50 Years of Cumulative Psychological Knowledge Solidifies Its Importance. Journal of Educational Psychology 101: 817-835.

Wolniak, Gregory C., and Ernest T. Pascarella. 2005. The Effects of College Major and Job Field Congruence on Job Satisfaction. Journal of Vocational Behavior 67: 233-251.

Wynn, Alison T., and Shelly J. Correll. 2018. Puncturing the Pipeline: Do Technology Companies Alienate Women in Recruiting Sessions? Social Studies of Science 48: 149-164.

Xie, Yu, and Kimberlee Shauman. 2003. Women in Science: Career Processes and Outcomes. Cambridge: Harvard University Press.

Xie, Yu, and Alexandra A. Killewald. 2012. Is American Science in Decline? Cambridge, MA: Harvard University Press.

Xie, Yu, Michael Fang, and Kimberlee Shauman. 2015. STEM Education. Annual Review of Sociology 41: 331-357.

Xue, Yi, and Richard C. Larson. 2015. STEM crisis or STEM surplus? Yes and yes. Monthly Labor Review, U.S. Bureau of Labor Statistics, May 2015. https://doi.org/10.21916/mlr.2015.14.

Publisher's Note Springer Nature remains neutral with regard to jurisdictional claims in published maps and institutional affiliations. 